\title{
FRICTION STIR WELDING OF ALUMINUM ALLOYS 6XXX SERIES: A REVIEW
}

\begin{tabular}{|c|c|c|}
\hline $\begin{array}{l}\text { Naveen Gadde } \\
\text { School of Mechanical Engineering, } \\
\text { Lovely Professional University, } \\
\text { Jalandhar, India. } \\
\text { e-mail: } \\
\text { gnaveenkumar1808@gmail.com }\end{array}$ & $\begin{array}{l}\text { Shikhar Goel } \\
\text { School of Mechanical Engineering, } \\
\text { Lovely Professional University, } \\
\text { Jalandhar, India }\end{array}$ & $\begin{array}{l}\text { Piyush Gulati } \\
\text { School of Mechanical Engineering, } \\
\text { Lovely Professional University, } \\
\text { Jalandhar, India }\end{array}$ \\
\hline
\end{tabular}

\begin{abstract}
Friction stir welding is a relatively new method of solid state joining of materials using non consumable tool. FSW is used in joining of metallic alloys which are difficult to weld using conventional method. The current paper focusses on the welding of the 6xxx series aluminum alloy. The following study is analysis of the effect of parameters and tool geometry on the microstructure, tensile strength and hardness of the joint obtained using FSW.
\end{abstract}

Keywords-6xxx series; Aluminum; Friction stir welding.

\section{INTRODUCTION}

Friction stir welding (FSW) was developed at the welding institute (TWI) in 1991 [1]. It is a solid state joining process which uses non consumable tool which is made to rotate over work piece. The typical tool consists of shoulder and profiled pin. During the welding process, the pin of rotating tool is plunged into work piece and shoulder touches upper surface of work piece. As a result of this frictional heat is developed between tool and work piece interface and plastic deformation of work piece takes place. The tool functions in two ways. (1) to heat the work piece (2) stirring of plasticized material. The localized heat will soften the material surrounding the pin, the translatory and rotary combined motions flow material from front to back of the pin. In this paper the study of 6xxx series aluminum alloy is carried out. 6xxx is widely used in aerospace and aircraft industry, automotive parts, pipes and tubing. Refer to "Fig. 1" schematic of the FSW.

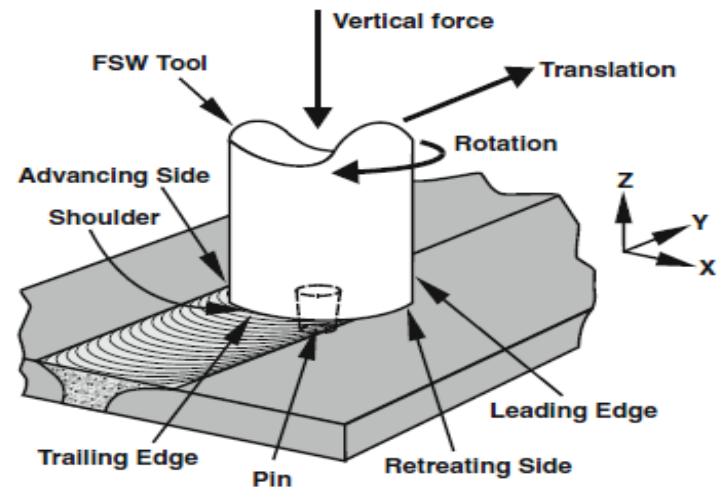

Fig. 1 Schematic FSW process [1]

\section{REVIEW OF LITERATURE}

Ouyang et al. [2] performed the study over the same and dissimilar alloys using the tool grade steel tool over the following configuration 6061-6061 \& 6061-2024 alloy with the parameters $151-914 \mathrm{rpm} \& 57-330 \mathrm{~mm} / \mathrm{min}$ with threaded tool. The vortex like structure formed is attributed as the result of the stirring action of the threaded tool, extrusion and tool traverse featured by the concentric rings for 6061-6061 Al and alternative lamellae by $6061-2024 \mathrm{Al}$. The nugget region is classified into the three regions Mechanically Mixed Region (MMR) featured by the dispersed particles of different alloy constituents, stirring induced plastic flow region (SPFR) characterized by vortex-like lamellae of two Al-alloys and the unmixed region (UMR) consisting of fine equiaxed grains of the 6061-Al alloy. The material in the vicinity of the tool is softened and behaves like the liquid of the high viscosity. At high welding speed like $229 \mathrm{~mm} / \mathrm{min}$ faster return flow is required to satisfy the continuity and the return flow takes a shortcut back to the surface instead of reaching the root, this results in the two or more rotating cells.

Huijie liu et al. [3] investigated the tensile properties and fracture locations in FSW of AA6060-T6 alloy of dimensions $30 \mathrm{~mm} \times 80 \mathrm{~mm}$ X $5 \mathrm{~mm}$. An HSS tool with diameter of shoulder and pin as $15,6 \mathrm{~mm}$ respectively with pin length of $4.7 \mathrm{~mm}$ and $3^{\circ}$ tilt angle. Rotation speed, weld speed and revolutionary pitch were taken as weld parameters in ranges $1000-1500 \mathrm{rpm}, \quad 100-1000 \mathrm{~mm} / \mathrm{min}, \quad 0.07-1.00 \mathrm{~mm} / \mathrm{r}$ respectively. They concluded that for $0.53 \mathrm{~mm} / \mathrm{r}$ of pitch, 1500 $\mathrm{rpm}$, welding speed of $800 \mathrm{~mm} / \mathrm{min}$, the maximum UTS of joint is about $77 \%$ of base metal. The tensile properties of welds degraded when revolutionary pitch deviated from the optional value and resulted in crack-line defect or serious softening. A fracture in HAZ on retreating side is observed when joints were defect free. Or else, when there was crackline defect in joints, fracture was observed in weld nugget. Fig. 2 represents experimental result.
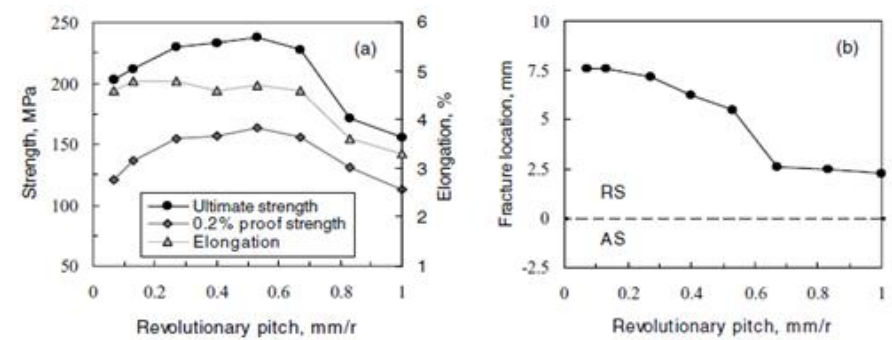

Fig. 2(a) Strength vs Revolutionary pitch \& 2(b)Fracture location vs Revolutionary pitch [3]

A. Gerlich et al. [4] studied the tool penetration in friction stir spot welding of $\mathrm{Al}$ and $\mathrm{Mg}$ alloys. $1.5 \mathrm{~mm}$ thick AZ91D, A16061-T6 and A15754-H12 and $1.3 \mathrm{~mm}$ thick Al6111-T4 were used in the study. Test specimen dimensions in all trails are $25 \mathrm{X} 100 \mathrm{~mm}$. An H13 steel tool with shoulder and pin 


\section{(2) \\ ELK \\ Asia Pacific Journals}

diameter as $10 \mathrm{~mm}$ and $4 \mathrm{~mm}$ respectively with pin length of $2.2 \mathrm{~mm}$. For some trails smooth unthreaded tool without shoulder was used with pin diameter as $4 \mathrm{~mm}$. The experiment was carried by taking rotational speed, plunge rate and penetration depth control in ranges of 1000-3000RPM, 0.1$10 \mathrm{~mm} / \mathrm{sec}$ and $\pm 0.1 \mathrm{~mm}$ respectively with axial load of $12 \mathrm{KN}$ as weld parameters. Based on observations they suggested that the delamination which took place for first $75 \mu \mathrm{m}$ of penetration into magnesium base metal is characteristic feature of mild wear. The weighted average tangential velocity at base of $4 \mathrm{~mm}$ diameter pin is $0.418 \mathrm{~m} / \mathrm{s}$ during FSW spot welding at rotation speed of $3000 \mathrm{rpm}$. The output was produced by adhesion and seizure events, which will continue till the rotating pin was completely covered with adhering film when the pin reaches depth of penetration of $500 \mu \mathrm{m}$ in both $\mathrm{Al}$ alloy and $\mathrm{Mg}$ base alloy. The tool penetration is progressive wear events from mild wear through severe wear and finally to melt wear in metal beneath the base of rotating pin. Melt wear may occur under tool shoulder if sufficient penetration of upper sheet is there during welding. The high temperature during FSW of Al6111 and AZ91 base materials are near to solidus temperature of each base metal and corresponds with $0.9 \mathrm{~T}_{\mathrm{s}}(\mathrm{Al6111})$ and $0.99 \mathrm{~T}_{\mathrm{s}}(\mathrm{AZ} 91)$ where $\mathrm{T}_{\mathrm{s}}$ is solidus temperature.

Hidetoshi Fujii et al. [5] investigated the effect of tool shape on the mechanical properties and microstructure of friction stir welded 1050-H24, 5083-O and 6061-T6 aluminum alloys with $300 \mathrm{~mm}$ X $70 \mathrm{~mm}$ X $5 \mathrm{~mm}$ as work piece dimensions. Three tools such as tool with columnar probe without threads, tool with columnar probe and threads; and tool with triangular prism probe. Probe length was $4.7 \mathrm{~mm}$, diameter of columnar probe circumscribed circle in triangular probe was $6 \mathrm{~mm}$, thread tool had right hand pitch of $0.5 \mathrm{~mm}$, diameter of smooth shoulder was $15 \mathrm{~mm}$ with concavity and tilt angle as $10^{\circ}$ and $3^{\circ}$ respectively. For $1050-\mathrm{H} 24$ rotation speed was $1500 \mathrm{rpm}$ with welding speed ranging from $100-700 \mathrm{~mm} / \mathrm{min}$ and revolutionary pitch ranging from $0.07-0.47 \mathrm{~mm} / \mathrm{r}$. For 6061-T6 rotation speed was $1500 \mathrm{rpm}$ with welding speed ranging from $100-1000 \mathrm{~mm} / \mathrm{min}$ and revolutionary pitch ranging from $0.07-0.67 \mathrm{~mm} / \mathrm{r}$. For $5083-\mathrm{O}$ rotation speed ranges from 600-1500 rpm, welding speed ranges between 25 $200 \mathrm{~mm} / \mathrm{min}$ and revolutionary pitch from 0.02-0.27 mm/r were taken as weld parameters. They concluded that for 1050 $\mathrm{H} 24$ there is low deformation resistance, columnar tool without threads will give weld having good mechanical properties, because tool shape induced defects less weld than other tools. For 6061-T6, which has less deformation resistance tool shape has no significant effect on microstructure and mechanical properties of joints. For 5083$\mathrm{O}$, which had high deformation resistance the rotational speed affects the weld ability. At high rotational speed about 1500 rpm the triangular prism tool suits best. And for medium rotational speeds about $800 \mathrm{rpm}$ the column with threads was best. Here the tool shape was not affecting the microstructure and mechanical properties of welding. For work pieces with high melting temperature which show less deformation resistance in FSW temperature range, columnar tool without threads will be good. For work pieces with high melting temperature which have high deformation resistance in FSW

\section{ELK Asia Pacific Journals - Special Issue} ISBN: 978-81-930411-4-7

temperature range, columnar tool without threads is used by decreasing rotational speed. And also profiled tool can also give good weld even at high welding speed.

Liu et al. [6] worked on the 6061Al-T651 alloy on the effect of tool dimension and welding speed. The changes in the shoulder diameter, pin diameter, rpm, welding speed influences the inclination of the LHZ (low hardness zone), but do not make any significant effect on its hardness. The variation of the thermal cycle is not significant by shoulder diameter, pin diameter, rpm but it is affected by welding speed. The tensile strength increased with increasing speed irrespective of shoulder, pin diameter and $\mathrm{rpm}$; and fractured at LHZ. Low density of $\beta^{\prime}$ precipitate lead to minimum hardness of LHZ. Fig. 3 represents welding parameters used.

\begin{tabular}{cccccc}
\hline Sample & Shoulder Diameter $(\mathrm{mm})$ & Pin Diameter $(\mathrm{mm})$ & Rotation Rate $(\omega), \mathrm{mm}$ & Welding Speed $(\mathrm{v}), \mathrm{mm} / \mathrm{min}$ & Designation \\
\hline 1 & 16 & 8 & 1400 & 400 & $16-8-1400-400$ \\
2 & 20 & 8 & 1400 & 400 & $20-8-1400-400$ \\
3 & 24 & 8 & 1400 & 400 & $24-8-1400-400$ \\
4 & 24 & 8 & 1400 & 600 & $24-8-1400-600$ \\
5 & 24 & 8 & 1400 & 200 & $24-8-1400-200$ \\
6 & 24 & 8 & 1200 & 200 & $24-8-1200-200$ \\
7 & 24 & 8 & 900 & 200 & $24-8-900-200$ \\
8 & 20 & 6 & 1400 & 400 & $20-6-1400-400$ \\
\hline
\end{tabular}

Fig. 3 Welding parameters [6]

Priya et al. [7] conducted work on 6061 and 2219 aluminum alloy plates (in T6 condition) with $1600 \mathrm{rpm}$ and $400 \mathrm{~mm} / \mathrm{min}$ on the effect of post weld heat treatment. The direct post welding heat treatment resulted in the nucleation of fine precipitates along with existing $\left(\mathrm{CuAl}_{2}\right)$ coarse precipitates but post weld solution treatment followed by ageing resulted in very fine precipitates. The solution treatment results in the dissolution of precipitates throughout the weld; rapid cooling, after it, results in the supersaturated state with large number of quenched vacancies; ageing following this process results in the homogeneous precipitation of these strengthening phases as a consequence of which hardness increases.

L. Karthikeyan et al. [8] conducted a study on relationship between process parameters and mechanical properties of friction stir processed AA6063-T6 aluminum alloy with 200 $\mathrm{mm}$ X $50 \mathrm{~mm}$ X $10 \mathrm{~mm}$ as work piece dimensions. The tool used was HSS with cylindrical shoulder and right hand threaded pin. Shoulder and pin diameter were $18 \mathrm{~mm}$ and 6 $\mathrm{mm}$ respectively with $5.7 \mathrm{~mm}$ pin length, rotational speed of $800,1000,1400,1600 \mathrm{rpm}$ is taken for each of 22.2, 40.2 and $75 \mathrm{~mm} / \mathrm{min}$ tool feed for each of 8,10 and $12 \mathrm{kN}$ of axial force were weld parameters. They concluded that the weld had refined and homogenized grain structure in microstructure. The great mechanical properties can be got with feed of 40.2 $\mathrm{mm} / \mathrm{min}$, rotational speed in range of $1200-1400 \mathrm{rpm}$ and axial force of $10 \mathrm{kN}$. Defect free welds with good microstructure was obtained by these properties. The maximum increase in UTS is $46.5 \%$, ductility is $133 \%$, micro hardness is $33.4 \%$ of the parent metal. Specimens in which welding is done at $8 \mathrm{kN}$ feed rate yielded process defects.

Alaadin Toktas et al. [9] investigated effect of Welding parameters and aging process on the mechanical properties of friction stir-welded 6063-T4 Al alloy with dimensions as 750 


\section{(2) \\ ELK \\ Asia Pacific Journals}

mm X $75 \mathrm{~mm}$ X $3.7 \mathrm{~mm}$. A DIN 1.2714 steel tool was used in the study with shoulder/pin diameter 3 and tilt angle $2^{\circ}$ with hardness of 45 HRC. Revolutionary pitch values of $0.25,0.40$; $0.18,0.28 ; 0.125,0.25 \mathrm{~mm} / \mathrm{rpm}$ each of welding speed of 200 and $315 \mathrm{~mm} / \mathrm{min}$ respectively for rotation speed of 800,1120 , $1600 \mathrm{rpm}$ respectively were weld parameters. They concluded that homogeneous hardness profile is got for all welds with no softening regions. Hardness value was increased with rise in rotation speed for both as-weld and post weld aging process. The hardness decreased little bit, most below the hardness value of base metal after post weld aging process. The effect of rotation speed on the tensile properties depends on weld speed and post weld aging process. The yield and UTS were increased by the rotation speed at low welding speed $(200$ $\mathrm{mm} / \mathrm{min}$ ) and/or the post weld aging process. A $315 \mathrm{~mm} / \mathrm{min}$ welding speed was good over $200 \mathrm{~mm} / \mathrm{min}$ as it gives high yield, UTS and bending forces. The post weld aging at $185^{\circ} \mathrm{C}$ for $7 \mathrm{hr}$ made no good results on the observed mechanical properties.

R. Palanivel et al. [10] studied the effect of tool rotational speed and pin profile on microstructure and tensile strength of dissimilar friction stir welded AA5083-H111 and AA6351-T6 aluminum alloys. The dimensions of work pieces were $100 \mathrm{~mm}$ X 50mm X 6mm. AA6351 was placed in advancing side and AA5083 was placed in retreating side. The tool used for study was made of high carbon high chromium steel with various pin profiles such as SS - straight square, SH - straight hexagon, SO - straight octagon, TS - Tapered square, TO tapered octagon. Flat shoulder surface with shoulder and pin diameter as 18, $6 \mathrm{~mm}$ respectively with $5.7 \mathrm{~mm}$ of pin length and $0^{\circ}$ tool tilt angle. Tool type and rotation speed 600, 950 and $1300 \mathrm{rpm}$ were weld parameters. Based on observations they concluded that the welds made of straight tool profiles had no defect but welds made of tapered tool made tunnel defect at the bottom of joints. In weld zone, three different regions called unmixed region, mechanically mixed region and mixed flow region can be seen. Tool rotational speed and pin profile are responsible for mixed flow region. The welds made by tapered tool profiles and rotational speed about 600 rpm has no mixed flow region. The weld made of square pin profile with rotational speed of $950 \mathrm{rpm}$ gives high yield strength of $273 \mathrm{MPa}$. The change in tensile strength of dissimilar joints was because of material flow behavior, loss of cold work in HAZ of AA5083, dissolution and over aging of precipitates and macroscopic defects in weld zone.

S. Malarvizhi et al. [11] conducted a study on Influences of tool shoulder diameter to plate thickness ratio $(\mathrm{D} / \mathrm{T})$ on stir zone formation and tensile properties of friction stir welded dissimilar joints of AA6061 aluminum-AZ31B magnesium alloys. The dimensions of work piece were $200 \mathrm{~mm}$ X 150 $\mathrm{mm}$ X $6 \mathrm{~mm}$. Al alloy was placed on retreating side and $\mathrm{Mg}$ alloy is placed on advancing side. HSS tool was taken for the experiment. Shoulder diameter of tool was varied by 2-4 times the thickness of the plate. Tapered pin profile with major to and minimum diameters of pin to be $6 \mathrm{~mm}$ and $5 \mathrm{~mm}$ respectively. Pin length was $5.7 \mathrm{~mm}$ with $0^{\circ}$ tool inclination. Tools with shoulder diameters of 12, 15, 18, 21, $24 \mathrm{~mm}$ were

\section{ELK Asia Pacific Journals - Special Issue} ISBN: 978-81-930411-4-7

used for study. The weld parameters were tool rotation speed of $400 \mathrm{rpm}$ with welding speed of $0.33 \mathrm{~mm} / \mathrm{s}$ and axial load of $12 \mathrm{kN}$. They concluded that the weld with tool shoulder of diameter $21 \mathrm{~mm}$ (3.5 times the plate thickness) yielded high tensile strength about $192 \mathrm{MPa}$ and weld efficiency was $89 \%$ as compared to the lower strength base metal. Dynamic re crystallization was enabled by the frictional heat from the shoulder of the tool nib, and then heat was generated by mechanical stirring of materials by nib. Complex intercalated microstructure in weld zone, with swirls and vortices show the flow pattern of the dissimilar metals. This type of microstructure leads to high hardness in weld zone.

P. janaki ramulu et al. [12] investigated internal defect and process parameter analysis during friction stir welding of $\mathrm{Al}$ 6061-T651 alloy sheets of $2.1 \mathrm{~mm}$ thickness. Three tools with flat shoulders of diameters of 12, 15 and $18 \mathrm{~mm}$, frustum pin with pin length and pin diameter to be $1.7 \mathrm{~mm}$ and $4 \mathrm{~mm}$ respectively and tilt angle of $2.5^{\circ}$ were used for experiment. Shoulder diameter, plunge depth, rotation speed and welding speed were taken as weld parameters. Based on experimental results they concluded that welds without internal defects were produced in higher welding speed $(80-120 \mathrm{~mm} / \mathrm{min})$, higher rotational speed (1300-1500 rpm), higher plunge depth (1.85-2 $\mathrm{mm})$. Defect free welds were produced by using 12, 15,18 $\mathrm{mm}$ shoulder diameters. Axial force and torque increases with increase in welding speed, shoulder diameter and decreases with increase in rotation speed. Axial force increases with increase in plunge depth and plunge depth has no effect on torque. There were no internal defects in weld region when optimized welding parameters are reached. In the range of taken parameters the axial force and torque are almost constant, shows that they are not sensitive to change in parameters. Fig. 4 represents welding parameters.

\begin{tabular}{|c|c|c|c|c|c|c|c|c|}
\hline \multirow[t]{3}{*}{ Trial } & \multicolumn{8}{|l|}{ Parameters } \\
\hline & \multirow[t]{2}{*}{ Pin length $(\mathrm{mm})$} & \multirow{2}{*}{$\begin{array}{l}\text { Shoulder diameter } \\
(\mathrm{mm})\end{array}$} & \multicolumn{2}{|c|}{$\begin{array}{l}\text { Plunge depth } \\
(\mathrm{mm})\end{array}$} & \multicolumn{2}{|c|}{$\begin{array}{l}\text { Tool rotational } \\
\text { speed (rpm) }\end{array}$} & \multicolumn{2}{|c|}{$\begin{array}{l}\text { Welding speed } \\
(\mathrm{mm} / \mathrm{min})\end{array}$} \\
\hline & & & Min & $\operatorname{Max}$ & Min & $\operatorname{Max}$ & Min & $\operatorname{Max}$ \\
\hline \multirow[t]{2}{*}{ I } & 1.7 & 18 & $\begin{array}{l}1.5 \\
1.9\end{array}$ & 1.9 & $\begin{array}{l}1,100 \\
800\end{array}$ & 1,600 & 90 & \\
\hline & & & & & 1,350 & & 50 & 100 \\
\hline \multirow[t]{2}{*}{ II } & & 15 & $\begin{array}{l}1.7 \\
1.9\end{array}$ & 2.0 & $\begin{array}{l}1,100 \\
1,200\end{array}$ & 1,500 & 90 & \\
\hline & & & & & 1,350 & & 90 & 130 \\
\hline \multirow[t]{3}{*}{ III } & & 12 & 1.75 & 2.0 & 1,300 & & 90 & \\
\hline & & & 2 & & 1,300 & 1,600 & 120 & \\
\hline & & & 1.9 & & 1,300 & & 90 & 130 \\
\hline
\end{tabular}

Fig. 4 Welding parameters [12]

H.K. Mohanty et al. [13] studied effect of tool shoulder and pin probe profiles on Friction Stirred aluminum welds of AA6063-T4. The tool used was made up of $48-53 \%$ of Fe, $0.25 \% \mathrm{C}, 24-26 \% \mathrm{Cr}, 2 \% \mathrm{Mn}, 19-22 \% \mathrm{Ni}$. Tool dimensions and weld parameters are as shown. They concluded that out of all types of tools profiles, straight cylindrical tool with $5 \mathrm{~mm}$ pin diameter and having minimum shoulder flat contact surface has high tensile strength. Weld cross sectional area varies proportionally with tensile strength of joint. Alloy cylindrical tool will give nice mechanical properties for low deformation resistance. When compared to the hardness of base metal, the weld nugget and TMAZ has little bit higher hardness. For commercial grade aluminum alloys, usage of trapezoidal and 


\section{(2) \\ ELK \\ Asia Pacific Journals}

tapered cylindrical tool on behalf of straight cylindrical tools did not enhance weld properties to good extent. For trapezoidal and cylindrical tools plunging face will be less at starting of weld. For AA6063-T4, the concave shoulder did not show effect on weld strength but served as an escape volume for the material displaced during plunging and traversing. Fig. 5 represents welding parameters.

\begin{tabular}{ccccccc}
\hline $\begin{array}{c}\text { Tool probe } \\
\text { profile }\end{array}$ & \multicolumn{3}{c}{ Tool probe diameter } & \multicolumn{3}{c}{ Tool shoulder flat surface } \\
\cline { 2 - 7 } & High & Medium & Low & High & Medium & Low \\
\hline $\begin{array}{c}\text { Trapezoidal } \\
\text { Tool }\end{array}$ & +1 & 0 & -1 & +1 & 0 & -1 \\
\hline $\begin{array}{c}\text { Tapered } \\
\text { cylindrical } \\
\text { tool }\end{array}$ & +1 & 0 & -1 & +1 & 0 & -1 \\
\hline $\begin{array}{c}\text { Straight } \\
\text { cylindrical } \\
\text { tool }\end{array}$ & +1 & 0 & -1 & +1 & 0 & -1 \\
\hline
\end{tabular}

Fig. 5 Welding parameters [13]

Firouzdor et al. [14] conducted the study on $6061 \mathrm{Al}$ and commercially pure $\mathrm{Cu}$ with the following parameters, sample CL-1 revealed that $\mathrm{CuAl}_{2}$ and $\mathrm{Cu}_{2} \mathrm{Al}_{4}$ intermetallic were formed in the conventional lap welds. In modified weld the $\mathrm{Al}$ to $\mathrm{Al}$ bonding is free from inter metallic compound so it is strong. When the sample ML-4 (1400 rpm and $203 \mathrm{~mm} / \mathrm{min}$ ) was tested then it was found that $\mathrm{NZ}$ in Al6061 consists of relatively large size particles embedded in matrix. The $\mathrm{Cu}$ from upper side is not pulled towards the $\mathrm{NZ}$ and no interlocking takes place. The channel exists in the lower left side in $\mathrm{NZ}$ of $\mathrm{Cu}$ side. The presence of channel decreases the strength and the ductility of the weld. Fig. 6 represents work piece combinations and weld parameters.

\begin{tabular}{llcc}
\hline$\#$ & \multicolumn{1}{c}{ Joint } & Rotation Speed (rpm) & Travel Speed (mm/min) \\
\hline CL-1 & Al (top) to Cu (bottom) & 1400 & 38 \\
CL-2 & Al (top) to Cu (bottom) & 1400 & 76 \\
CL-3 & Al (top) to Cu (bottom) & 1400 & 127 \\
CL-4 & Al (top) to Cu (bottom) & 1400 & 203 \\
ML-1 & Top: Cu (ret) and small Al (adv); Bottom: Cu & 1400 & 38 \\
ML-2 & Top: Cu (ret) and small Al (adv); Bottom: Cu & 1400 & 76 \\
ML-3 & Top: Cu (ret) and small Al (adv); Bottom: Cu & 1400 & 127 \\
ML-4 & Top: Cu (ret) and small Al (adv); Bottom: Cu & 1400 & 203 \\
\hline
\end{tabular}

Fig. 6 Workpiece combinations and weld parameters [14]

Aval et al. [15] worked with AA5086-O (AS) \& AA6061T6 using H13 tool with $600-1000 \mathrm{rpm} \& 30-150 \mathrm{~mm} / \mathrm{min}$ to conclude the residual effect distributions. The distribution of the $\mathrm{Mg}$ showed that with increase in the rpm and decrease in welding speed the mixing of material in nugget is more efficient. The HAZ effected by thermal cycling gets it precipitate $\beta^{\prime \prime}$ needle to $\beta^{\prime}$ rod shape. The longitudinal residual stress values in NZ are approx. zero, the residual stress in HAZ in both lateral and longitudinal case is high, and it is related to high heat input during FSW.

Liu H.J. et al. [16] analysed the effect of welding speed on properties of self-reacting tool welded specimen using 6061T6 Al alloy with $600 \mathrm{rpm} \& 50-250 \mathrm{~mm} / \mathrm{min}$. NZ formed is of hour glass shaped due to the self-reacting tool, the band formation is observed from AS to the NZ center the grains in the band are highly refined. The HAZ zone is affected by the thermal cycling, when the welding speed increases from $50 \mathrm{~mm} / \mathrm{min}$ to $200 \mathrm{~mm} / \mathrm{min}$ the density of $\beta^{\prime}$ is increased along with reduction in size from $230 \mathrm{~nm}$ to $150 \mathrm{~nm}$, due to the thermal cycling the size of $\beta$ ' was reduced due to dissolution.

\section{ELK Asia Pacific Journals - Special Issue} ISBN: 978-81-930411-4-7

$\beta^{\prime \prime} \& \beta^{\prime}$ were not observed in TMAZ, all the metastable phases have been diminished this implies the serious effect of thermal cycling in the case of the self-reacting friction stir welding.

The hardness of TMAZ and HAZ was improved at higher welding speed leading to the decrease of softened zone width this is due to the fine precipitates of $\beta^{\prime \prime}$ and $\beta^{\prime}$ in the matrix of Al. Micro hardness value was lowest in AS. The tensile strength value decrease with increase in the traverse speed, maximum tensile strength achieved is $69 \%$ to that of BM. All the defects free joints shows necking phenomenon.

I. Galvao et al. [17] investigated on influence of aluminum alloy type on dissimilar friction stir lap welding of aluminum to copper. AA-6082_T6 and AA-5083-H111 alloys of $6 \mathrm{~mm}$ thick and Copper- DHP (R240) of $1 \mathrm{~mm}$ thick was used for study. A conical shoulder tool with $9.5 \mathrm{~mm}$ diameter and probe of diameter $3 \mathrm{~mm}$ with length $1 \mathrm{~mm}$ and cavity of $8^{\circ}$ was used. Rotational speed of $600 \mathrm{rpm}$ and traverse speed of $50 \mathrm{~mm} / \mathrm{min}$ were weld parameters. Weld with this configuration (Copper-DHP/AA5083-H111) is W5 and weld with this configuration (Copper-DHP/AA6082-T6) is W6. They concluded that AA5083/Copper-DHP welds have great surface finish but has high defective interfaces $(\mathrm{Al} / \mathrm{Cu})$, without any signs of base material interaction. The AA6082/copper-DHP welds showed less surface finish but have very good base materials mixing in interface zone. The AA5083/copper-DHP welds have good and increased hardness in the aluminum part because of the formation of the ultra-refined microstructure. In this experiment the very small tool that was used has a major role in micro structural evolution of AA5083H111 aluminum alloy during welding.

H. jamshad aval et al. [18] conducted a study on natural aging behavior and mechanical properties of friction stir-welded AA 6061-T6 plates of $5 \mathrm{~mm}$ thick. A HSS tool with shoulder diameter of $20 \mathrm{~mm}$, Conical probe with 3 grooves of 3-6 mm diameter and $4.8 \mathrm{~mm}$ length, conical concavity of $2^{\circ}$ with inclination angle of $1^{\circ}$ was used. The natural aging time is 250 days at room temperature. The rotational speed was taken as $840 \mathrm{rpm}$ for weld speeds of $10 \mathrm{~cm} / \mathrm{min}, 15 \mathrm{~cm} / \mathrm{min}$ and rotational speed of $900 \mathrm{rpm}$ was taken for weld speeds of 10 $\mathrm{cm} / \mathrm{min}, 15 \mathrm{~cm} / \mathrm{min}$ were weld parameters. They concluded that there is decrease in hardness across welded joints because of partial dislocation and coarsening of hardening particles. Mechanical properties are affected for first 14 days and effect is considerably decreased in longer aging durations. Due to natural aging, longitudinal and transverse residual stress in stir zone were decreased no difference was seen in base metal and HAZ. The particle morphologies in HAZ are rod and round shaped. But in TMAZ the rod shaped precipitates are dissolved and precipitates with diameters about 50-200 nm are observed.

Cole et al. [19] studied temperature effects during FSW for 6061-T6 and 7075-T6 Al. 6061-T6 has high solidus temperature so placed on AS. Tool of H13 tool steel with a $4.4^{\circ}$ concave shoulder \& threaded, conical pin with three flats is used, 700 to $1450 \mathrm{rpm}$ with increments of $150 \mathrm{rpm}$ and 100 


\section{(2) \\ ELK \\ Asia Pacific Journals}

to $150 \mathrm{~mm} / \mathrm{min}$ with $25 \mathrm{~mm} / \mathrm{min}$ increment. The average temperature for the tool offset range from -2 to $2 \mathrm{~mm}$. The observation suggests that the average temperature (on AS, RS for shoulder and Pin) increased when the tool offset was +2 $\mathrm{mm}$ i.e. towards the Al6061 side. This determines the amount of heat treatment the specimen was subjected to and finally the strength. The average temperature at the shoulder was more than the temperature at the pin for the case of dissimilar weld. As the tool was offset towards the Al 7075 side the temperature is reduced which refers that when the heat input is less when the tool offset towards the alloy with low solidus temperature. The lowered speed leads to the increase in the average temperature and hence the strength of the alloy suffers.

Ghosh et al. [20] worked on FSW of 304SS to 6061 Al alloy using WC tool on $560-900 \mathrm{rpm}$ and $0.5 \mathrm{~mm} / \mathrm{sec}$ welding speed. The tool traverse in the inclined path in such a way that after traversing $100 \mathrm{~mm}$ distance the penetration of the pin is only $20 \%$ of its diameter. This technique was used to avoid the super heating of the $\mathrm{Al}$ alloy as a result of friction between the toll and the aluminum alloy. The peak hardness was greater than the hardness of the parent metals, this increase in the value above the parent alloy is attributed to the formation of the composite produced by stirring action of pin and formation of harder phase near the interface. This hardness is also attributed to the formation of intermetallic phase $\mathrm{FeAl}+\mathrm{FeAl}_{3}$ near the interface the hardness of which may be up to $641 \mathrm{HV}$. At low heat input, the only $\mathrm{Fe}_{2} \mathrm{Al}_{5}$ was formed near interface. When the temperature in $\mathrm{NZ}$ increased, $\mathrm{Fe} 3 \mathrm{Al}$ and $\mathrm{FeAl}_{2}$ appeared. The hardness at the interface depends on the intermetallic formed at low speed it is low, then increases with increase in rpm, and finally drops.

Song et al. [21] studied influence of probe offset distance on microstructure and mechanical properties of friction stir butt welded joint of Ti6Al4V (on AS) with slight offset towards Titanium and A6061 alloy. The joint b/w Ti6Al4V and A6061 was formed due to the formation of Ti-Al compound at joint interface. The sound joint was obtained under probe offset 0.9$1.2 \mathrm{~mm}$ at $750 \mathrm{rpm}$ and $120 \mathrm{~mm} / \mathrm{min}$. At $1000 \mathrm{rpm}$ sound joints were obtained at tool offset of $0.6 \mathrm{~mm}$. When the tool offset was $1.2 \mathrm{~mm}$ at $100 \mathrm{rpm}$, the tensile strength fall and the specimen breaks at the interface rather than the HAZ region. This was attributed to the presence of IMC layers which causes brittle fracture. The EDS analysis revealed the presence of the thick TiAl3 compound (in $1.2 \mathrm{~mm}$ offset case) which is brittle in nature.

Wan et al. [22] studied Mechanical Properties and Microstructure of 6082-T6 Aluminum Alloy Joints by Selfsupport Friction Stir Welding at $800 \mathrm{rpm}$ and $10-200 \mathrm{~mm} / \mathrm{min}$. The heat input per unit length is a function of welding speed which affects softening and flow ability of plasticized material. Single onion rings were replaced by series of rings stacked vertically over the thickness on AS using SSFSW. The band pattern exists in the upper NZ from the AS towards the $\mathrm{NZ}$ center caused by the unsteady flow of material leading to
ELK Asia Pacific Journals - Special Issue

ISBN: 978-81-930411-4-7

the formation of smooth narrow interface between NZ and TMAZ on the advancing side. While at low welding speed the heat supplied to material was more and then wider was the softened area around the stirring tool causing improved metal flow and more effective bonding. Tensile strength increases with increase in welding speed. It reaches its maximum at the welding speed of $200 \mathrm{~mm} / \mathrm{min}$, and the joint efficiency is $69 \%$. The ductility of joint follows the opposite way to the tensile strength, and its maximum value is $12.58 \%$.

Zhao et al. [23] studied defects and tensile properties of 6013 aluminum alloy T-joints by friction stir welding at $1000 \mathrm{rpm}$, $100-400 \mathrm{~mm} / \mathrm{min}$ with $\mathrm{H} 15$ steel tool. The $\mathrm{T}$ joint was prepared with $2.5 \times 210 \times 110 \mathrm{~mm}$ alloy. The T lap \& T-butt lap joint is prepared with corner fillet of size $3 \mathrm{~mm} \& 2 \mathrm{~mm}$, the corner fillet ensures the rounding transition between the skin and stringer. With high traverse speed the heat input was decreased, and the flow ability was decreased and the tunnel defect formation took place. With more fillet radius the more metal was required to fill the cavity and hence the tunnel defect was more pronounced. The kissing bond defect exist at the double corner of each joint, the kissing bond defect was more pronounced at increased speed, it is mainly formed due to the lack of inter mixing of the material which do not experience stirring effect. The stirring effect was more at AS than on RS so kissing bond was more pronounced at the RS. When tested along the skin the specimen with no tunnel defect fails at retreating side due to the kissing bond. The specimen with tunnel defect failed at advancing side, the crack starts at the retreating side and propagate up to the tunnel defect (tunnel defect is towards RS here), in the meantime the crack was generated at kissing bond on AS. The specimen fails at the AS, it means that presence of the tunnel defect do not affect the strength but it is governed by kissing bond defect characterized by brittle fracture. The T-butt- lap $\mathrm{R}=2 \mathrm{~mm}$ joint shows more strength at $200 \mathrm{~mm} / \mathrm{min}$.

J.F. Guo et al. [24] based on his study concluded that when AA6061 alloy is located on the advancing side, then material mixed very effectively and multiple vortexes are vertically formed in centre of nugget. The weld of mixed weld have three different sub layers called AA6061 alloy sub layer and AA7075 alloy sub layer and mixed sub layer of two alloys. The thickness of onion ring sub layers were one-third of the advance per revolution measured at 30-100 $\mu \mathrm{m}$. Both AA6061 and AA7075 alloys had dynamic recrystallization and grain size in both alloys decreased with increase in weld speed. The grain size of AA7075 alloy sub-layer is much smaller than AA6061 sub-layer in same weld. Both metals have shown micro hardness decrease in weld compared to respective base metals. All joints failed at the positions in HAZ on the AA6061 side where the minimum hardness was located and had good tensile and ductility. The highest UTS is in D5 is $245 \mathrm{MPa}$ which is $32 \%$ higher than required in AWS standard on FSW.

Jingqing Zhang et al. [25] investigated on dissimilar underwater friction stir lap welding of 6061-T6 aluminum alloy $8 \mathrm{~mm}$ thick of pure copper plate was $2 \mathrm{~mm}$ thick. The 


\section{(2) \\ ELK \\ Asia Pacific Journals}

work piece dimensions were $200 \mathrm{~mm}$ X $100 \mathrm{~mm}$. A tool with shoulder radius, pin top and bottom radius, pin lengths were 8 $\mathrm{mm}, 2 \mathrm{~mm}, 1.5 \mathrm{~mm}, 4 \mathrm{~mm}$ respectively. The weld parameters were welding velocity of $30 \mathrm{~mm} / \mathrm{min}$, tool angular velocity of $1000 \mathrm{rpm}$, plunge depth of $0.2 \mathrm{~mm}$. Based on investigations they suggested that under water FSW decrease the peak temperature and will lessen then working time. (Thermal cycling time). Peak temperature of classical FSW was around $850 \mathrm{~K}$ and of underwater FSW is about $821 \mathrm{~K}$. Under water prevent the weld from oxidizing in under water FSW. In classical FSW the metal flows in horizontal direction but in under water FSW the metal will flow in vertical direction. The inter metallic compounds of $\mathrm{Al}$ and $\mathrm{Cu}$ namely $\mathrm{CuAl}_{2}$, $\mathrm{Cu}_{9} \mathrm{Al}_{4}$ together with some parts of $\mathrm{Al}$ and $\mathrm{Cu}$ are less in under water FSW and more in classical FSW. In classical FSW we see an obvious diffusion inter layer nearly $18 \mu \mathrm{m}$ thick at weld interface but for under water FSW the interlayer is much thin about $2 \mu \mathrm{m}$ thick.

Junying et al. [26] worked on friction stir blind riveting for aluminum alloy sheets of AA6111-T4 of $0.9 \mathrm{~mm}$ thickness and AA6022-T4 of $2.0 \mathrm{~mm}$ thickness. Dimensions of sheets were $38 \mathrm{~mm} \mathrm{X} 127 \mathrm{~mm}$ rivet shank diameters were $4.8 \mathrm{~mm}$ and $6.4 \mathrm{~mm}$. Spindle speed of 3000, 6000 and $9000 \mathrm{rpm}$ and feed of 120, 420 and $780 \mathrm{~mm} / \mathrm{min}$ were taken as parameters. Various combinations of rivets are to be produced. Each combination of rivet was done of each feed rate and each spindle speed. They concluded that by increasing the friction between the mandrel an spindle fixture, the force on shank by the spindle fixture is reduced. Blind rivet can bear high forces and torque loads by increasing the tolerance of rivet. By using spindle speed of $6000 \mathrm{rpm}$ and feed rate of 120, $180 \mathrm{~mm} / \mathrm{min}$ the process had less effect. Thicker work pieces and larger rivets need larger energy and load $\left(\mathrm{P}_{\max }\right)$. Spindle speed had its effect on $\mathrm{P}_{\max }$ and feed rate. Fig. 7 represents dimensions and forces, Fig. 8 represents rivets combinations.

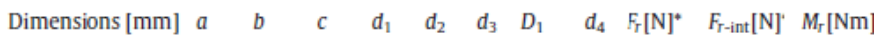
\begin{tabular}{llllllllllll}
\hline Small rivet & 7.2 & 10.3 & 2.0 & 4.8 & 4.5 & 3.2 & 9.6 & 1.9 & 5309 & 1643 & 2.4
\end{tabular} $\begin{array}{llllllllllll}\text { Large rivet } & 9.0 & 13.8 & 2.6 & 6.4 & 6.1 & 4.2 & 13.1 & 2.6 & 10220 & 2886 & 6.2\end{array}$

Fig. 7 Dimensions of rivets and forces [26]

\begin{tabular}{lllll} 
Combinations & I & II & III & IV \\
\hline Rivets & Small rivet & & & Large rivet \\
Upper workpiece & AA6111 & AA6022 & AA6111 & AA6022 \\
Lower workpiece & AA6111 & AA6022 & AA6022 & AA6022 \\
\hline
\end{tabular}

Fig. 8 Rivets combinations [26]

Fu et al. [27] performed FSW over dissimilar 6061T6aluminum alloy to AZ31B magnesium alloy using $800 \mathrm{rpm}$ \& $50 \mathrm{~mm} / \mathrm{min}$ by $\mathrm{H} 13$ Quenched \& Tempered to $50 \mathrm{HRC}$ tool. The placing of $\mathrm{Mg}$ on the advancing side lead to removal of defects and more homogeneous mixing. A small cavity was observed when the tool offset is zero in $\mathrm{Mg}-\mathrm{Al}$ configuration. In $\mathrm{Mg}$-Al configuration when the tool was given offset towards $\mathrm{Al}$ the area defects increased. When the tool speed was varied (with tool offset $+0.3 \mathrm{~mm}$ ) from 600 to $800 \mathrm{rpm} \&$ traverse speed was in the range 30 to $60 \mathrm{~mm} / \mathrm{min}$, sound weld

\section{ELK Asia Pacific Journals - Special Issue} ISBN: 978-81-930411-4-7

with no defect is obtained. The Energy dispersive X-ray analysis of IMCs of specimen obtained at $700 \mathrm{rpm}, 60$ $\mathrm{mm} / \mathrm{min}$ with $\mathrm{Mg}$ on $\mathrm{AS}$ and offset $+0.3 \mathrm{~mm}$ revealed the presence of the $\mathrm{Al}, \mathrm{Mg}$ content, the variation of contents suggested that layers of $\mathrm{Al}_{12} \mathrm{Mg}_{17} \& \mathrm{Al}_{3} \mathrm{Mg}_{2}$ were present. Welding condition was affected by two factors heat input and level of heat input to materials. The heat input was varied from rotation rate and welding speed.

Aval et al. [28] worked on the influence of pin profile on micro structure and mechanical behavior for FSW welded AA6082 (on AS) -AA7075 alloy with $1000 \mathrm{rpm}, 12 \mathrm{~cm} / \mathrm{min} \&$ $1200 \mathrm{rpm}, 10 \mathrm{~cm} / \mathrm{min}$. The conical tool produced highest temperature due to more contact surface. Decrease in weld pitch (ratio of welding speed to rotational speed) from 0.075 to 0.012 resulted in decrease in coarse grain size along with the decrease in strength of the joint produced. When compared in terms of tool profiles, the samples joined by the conical probe were possessing more grain size than those joined by square frustum probe because of less pulsating action generated by the conical tool and more temperature due to more surface area in contact. The material mixing in NZ was more uniform with square frustum probe.

Zhao et al. underwater FSW of AA6013 (on AS) aluminum and AZ31 magnesium alloy using $\mathrm{H} 13$ tool at $1200 \mathrm{rpm} \& 80$ $\mathrm{mm} / \mathrm{min}$ the sound weld is obtained under these parameters. The IMC layer formed in the underwater is much thinner than produced in air welded. The highest micro hardness appeared along the center line but it was less than base material $6013 \mathrm{Al}$ alloy. On testing the joint failed at the center where hardness gradient was sharpest, it failed through brittle fracture, XRD revealed the presence of $\mathrm{Al}_{3} \mathrm{Mg}_{2} \& \mathrm{Mg}_{17} \mathrm{Al}_{12}$ on both side of fracture surface.

\section{CONCLUSION}

Much of research work has been done on 6xxx Al alloy. Based on their research work the following points are listed as.

1. The hardness of HAZ is affected by thermal cycling, coarsening of precipitates leads to decrease in the hardness.

2. The fine grain size promote the strength

3. The underwater friction stir welding decrease the heat input and promote the refinement of grain size which in turn increases the strength and hardness of the joint.

4. The site of fracture is the area of lowest hardness or the area of high hardness gradient.

5. The materials with high strength when placed on the advancing side give superior welds.

6. The inter metallic compounds formed do not affect the joint strength up to certain level but on further increase in thickness leads to failure of the joint by mode of brittle fracture. 


\section{(2) \\ ELK \\ Asia Pacific Journals}

\section{References}

[1] R. S. Mishra and M. W. Mahoney, "Friction Stir Welding and Processing," p. 368, 2007.

[2] J.H. Ouyang and R. Kovacevic. Materail flow and microstructure in friction stir butt welds of same and disimilar aluminum alloys. JMEPEG (2002) 11:51-63.

[3] H. Fujii, M. Maeda, K. Nogi, Journal of materials science letters 22, $1061-1063$, april 2003.

[4] A. Gerlich, P. Su, T. H. North, Journal of materials science 40, 6473-6481, october 2005.

[5] Hidetoshi Fujii, Ling Cui, Masakatsu Maeda, Kiyoshi Nogi, Materials Science and Engineering A 419, 25-31, November 2005.

[6] F.C. Liu and Z.Y. Ma. Influence of Tool Dimension and Welding Parameters on Microstructure and Mechanical Properties of Friction-Stir-Welded 6061-T651 Aluminum Alloy. Metallurgical and materials transactions a volume 39a, October 2008-2378-2388.

[7] R. Priya, V. SubramanyaSarma and K. Prasad Rao. Effect of post weld heat treatment on the microstructure and tensile properties of dissimilar friction stir welded AA 2219 and AA 6061 alloys. Transactions of The Indian Institute of Metals Vol. 62, Issue 1, February 2009, pp. 1119.

[8] L. Karthikeyan, V.S. Senthil Kumar, Materials and Design 32, 3085-3091, January 2011.

[9] Alaaddin Toktas, and Gu“lcan Toktas, JMEPEG, 21:936945, May 2011.

[10]R. Palanivel, P. Koshy Mathews, N. Murugan, I. Dinaharan, Materials and Design 40, 7-16, March 2012.

[11] S. Malarvizhi, V. Balasubramanian, Materials and Design 40, 453-460, April 2012.

[12]P. janaki ramulu, R. Ganesh Narayan, Satish v. Kailas , Jayachandra Reddy, Int J Adv Manuf Technol, 65:15151528- June 2012.

[13] H. K. Mohanty, M. M. Mahapatra, P. Kumar1, P. Biswas and N. R. Mandal, J. Marine Sci. Appl. 11: 200-207, June 2012.

[14] Vahid Firouzdor and Sindo Kou. Al-to-Cu Friction Stir Lap Welding. Metallurgical and materials transactions a volume 43a, January 2012-303-315.

[15] H. JamshidiAval, S. Serajzadeh, N. A. Sakharova, A. H. Kokabi, A. Loureiro. A study on microstructures and residual stress distributionsin dissimilar friction-stir welding of AA5086-AA6061. J Mater Sci (2012) 47:5428-5437.

[16] H.J. Liu, J.C. Hou, H. Guo. Effect of welding speed on microstructure and mechanical properties of self-reacting friction stir welded 6061-T6 aluminum alloy. Materials and Design 50 (2013) 872-878.
ELK Asia Pacific Journals - Special Issue ISBN: 978-81-930411-4-7

[17] I. Galvao, D. verdera, D. gesto, A. loureiro, D.M. Rodrigues, Journal of Materials Processing Technology 213, 1920-1928, May 2013.

[18]H. Jamshidi Aval \& S. Serajzadeh, Int J Adv Manuf Technol , 71:933-941, December 2013.

[19]E. G. Cole, A. Fehrenbacher, N. A. Duffie, M. R. Zinn, F. E. Pfefferkorn, N. J. Ferrier. Weld temperature effects during friction stirwelding of dissimilar aluminum alloys 6061-t6 and 7075-t6. Int J AdvManufTechnol (2014) 71:643-652.

[20] M. Ghosh, R.K. Gupta, and M.M. Husain. Friction Stir Welding of Stainless Steel to Al Alloy:Effect of Thermal Condition on Weld Nugget Microstructure. Metallurgical and materials transactions a volume 45a, February 2014 854-863.

[21]Zhihua Song, Kazuhiro Nakata, Aiping Wu, Jinsun Liao, Li Zhou. Influence of probe offset distance on interfacial microstructure and mechanical properties of friction stir butt welded joint of Ti6Al4V and A6061 dissimilar alloys. Materials and Design 57 (2014) 269-278.

[22] Long Wan, Yongxian Huang, ZongliangLv, ShixiongLv, Jicai Feng. Effect of self-support friction stir welding on microstructure and microhardness of 6082-T6 aluminum alloy joint. Materials and Design 55 (2014) 197-203.

[23] Yong Zhao, Lilong Zhou, Qingzhao Wang, Keng Yan, JiashengZou. Defects and tensile properties of 6013 aluminum alloy $\mathrm{T}$-joints by friction stir welding. Materials and Design 57 (2014) 146-155.

[24] J.F. Guo, H.C. Chen, C.N. Sun, G. Bi, Z. Sun, J. Wei, Materials and Design 56, 185-192, November 2014.

[25] Jingqing Zhang, Yifu Shen, Xin Yao, Haisheng Xu, Bo Li, Materials and Design 64, 74-80, July 2014.

[26] Junying Min, Jingjing Li, Yongqiang Li, Blair E. Carlson, Jianping Lin, Wei-Ming Wang, Journal of Materials Processing Technology 215, 20-29, August 2014.

[27]Banglong Fu, Guoliang Qin, Fei Li, XiangmengMeng, Jianzhong Zhang, Chuansong Wu.Friction stir welding process of dissimilar metals of 6061-T6aluminum alloy to AZ31B magnesium alloy. Journal of Materials Processing Technology 218 (2015) 38-47.

[28] HamedJamshidiAval. Influences of pin profile on the mechanical and microstructural behaviors in dissimilar friction stir welded AA6082-AA7075 butt Joint. Materials and Design 67 (2015) 413-421.

[29] Yong Zhao, Zhengping Lu, Keng Yan, Linzhao Huang. Microstructural characterizations and mechanical properties in underwater friction stir welding of aluminum and magnesium dissimilar alloys. Materials and Design 65 (2015) 675-681. 